\title{
Romatolojik hastalıklarda tuzak nöropatileri: Konservatif tedavi
}

\section{Entrapment neuropathies in rheumatologic diseases: Conservative treatment}

\author{
Banu Dilek
}

Dokuz Eylül Üniversitesi Tıp Fakültesi, Fiziksel Tıp ve Rehabilitasyon Anabilim Dalı, İzmir, Türkiye

Öz

Tuzak nöropatiler üst ve alt ekstremitede görülmektedir. Konservatif tedavi yaklaşımları cerrahi öncesi mutlaka denenmelidir. Bu derlemede romatizmal hastalıklarda sık görülen tuzak nöropatiler ve konservatif tedavi önerilerinin kanıta dayalı veriler eşliğinde sunulması amaçlanmıştır.

Anahtar Sözcükler: Romatolojik hastalık, tuzak nöropati, konservatif tedavi.

\begin{abstract}
Entrapment neuropathies affect the upper and lower extremities. Conservative treatment approaches should be tried before surgery. In this review, it is aimed to present entrapment neuropathies frequently seen in rheumatic diseases and conservative treatment recommendations with evidencebased data.
\end{abstract}

Keywords: Rheumatic disease, entrapment neuropathies, conservative treatment.

Tuzak nöropatileri duyusal, motor ve otonom sinir liflerini içeren periferik sinirlerin anatomik gidiş yolları boyunca bir fibröz veya fibro-osseöz tünel içinde sıkışması veya mekanik distorsiyonu ile oluşan fokal kompresyon nöropatileridir. Her periferik sinirin anatomik olarak tuzaklanmaya daha elverişli kısımları olmasına karşın tuzaklanma, sinir boyunca herhangi bir noktada da olabilir (1). Üst ve alt ektremiteyi etkileyen pek çok tuzak nöropati tanımlanmıştır (Tablo-1). Konservatif tedavi seçeneklerinde istirahat (provoke edici pozisyonlardan kaçınmak, splintleme), ödemi azaltma (soğuk uygulama ve non-steroid anti-inflamatuvar ilaçlar), fizik tedavi ajanları, egzersiz ve kortikosteroid enjeksiyonları önerilmektedir $(1,2)$. Bu derlemede sıklıkla görülen tuzaklanmalarda konservatif tedavi seçenekleri kanıta dayalı veriler ışığında ele alınacaktır.

\section{Karpal Tünel Sendromu (KTS)}

Hasta eğitimi ve aktivite modifikasyonu: Provoke eden pozisyonlardan kaçınmak çok önemlidir. Bileğin aşırı fleksiyon/ekstensiyon pozisyonu, kontakt stres, aşırı kullanma ve vibrasyon önlenmelidir (3).

Tablo-1. Sık görülen tuzak nöropatiler.

\begin{tabular}{|ll|}
\hline \multicolumn{1}{|c|}{ Üst Ekstremite } & \multicolumn{1}{c|}{ Alt Ekstremite } \\
- Torasik Çıkış Sendromu & - Siyatik Sinir Tuzaklanması \\
- Karpal Tünel Sendromu & - Peroneal Sinir Tuzaklanması \\
- Anterior İnterosseoz Sinir & - Tarsal Tünel Sendromu \\
Sendromu & - Meralgia Parestetica \\
- Pronator Teres Sendromu & - Femoral Sinir Lezyonları \\
- Kubital Tünel Sendromu & - Morton Nöroması \\
- Guyon Kanalı Sendromu & - Obturator Sinir Tuzaklanması \\
- Radial Sinir & Genitofemoral Sinir \\
Tuzaklanmaları & Tuzaklanması \\
& - Plioinguinal sinir tuzaklanması \\
& \\
& \\
\hline
\end{tabular}

El bileğinin fleksiyon ve ekstensiyonu sırasında karpal tünel içindeki basınç 8-10 kat artmaktadır. İş gereği 8 saat süre ile el bileğinin $3,9 \mathrm{~m} / \mathrm{sn}$ hızda tekrarlayan fleksiyon ekstensiyon aktivitesi ile çalışması sonucu (ortalama 4 kg'ık ağırlığın üstüne denk gelmekte) KTS oluşabilmektedir (4). 
İstirahat splinti: Splintler gece parestezilerini azaltır. Değişik açılarda olabilir (nötral >20 derece ekstensiyonda). Kombine tedavilerde kullanımı önerilmektedir. İlk 2-3 haftada semptomlar geriler. Gece daha çok önerilse de gün boyu kullanımının hem semptom hem de elektrofizyolojik açıdan daha iyi olduğu bildirilmektedir (5). 2012 yılında yayınlanan 1190 hasta, 19 randomize kontrollü çalışmayı içeren Cochrane derlemesine göre; KTS'de gece splintinin kullanımı hiçbir şey takmamaktan daha iyi bulunmuştur. Splint tasarımları arasında fark saptanmamıştır. Splint kullanımının egzersizden daha iyi olduğu sonucuna varılamamıştır (6).

Egzersiz: Tendon ve sinir kaydırma egzersizleri önerilmektedir (Şekil-1 ve Şekil-2). Yapılan bir çalışmada KTS olan hastalarda $(n=36) 4$ hafta tüm gün nötral splint ile birlikte tendon ve sinir kaydırma egzersizinin yapılması tek başına splint takılmasına göre semptomatik olarak daha iyi olsa da fonksiyonel açıdan anlamlı istatistiksel fark bulunamamıştır (8). Sinir kaydırma egzersizleri ile ilgili de sınırlı sayıda çalışma mevcuttur. Konservatif tedavide diğer yöntemlerle kombinasyon önerilmektedir. Parafin banyosu + splint + egzersiz ve ultrason + splint + egzersiz kombinasyonu ile daha etkili sonuçlar bildirilmektedir $(9,10)$. Tendon kaydırma ve sinir kaydırma egzersizlerinin tek başına karşılaştırıldığı bir çalışmaya rastlanamamıştır.

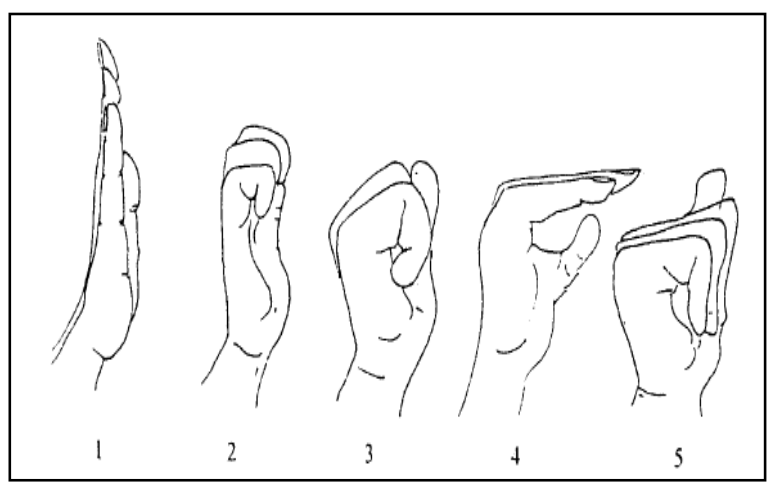

Şekil-1. Tendon kaydırma egzersizleri.

Fizik tedavi modaliteleri: Miyofasyal masaj terapi, ultrason, şok dalga tedavisi (ESWT), interferansiyel akım, iyontoforez, kısa dalga diatermi, lazer ve parafin banyosu önerilen tedaviler içindedir. Bu modalitelerin aktif artrit varken uygulanması önerilmemektedir. Sistematik derlemelerde bu yöntemlerin ağrı ve semptomların azalması, fonksiyonda iyileşme üzerine kısa ve orta vadede orta derece kanıt düzeyine sahip olduğu bildirilmiştir. Ancak optimal tedavi parametreleri ve doz yeterince çalışıımamış olup uzun dönem sonuçları ile ilişkili çalışmalara intiyaç bulunmaktadır (11).

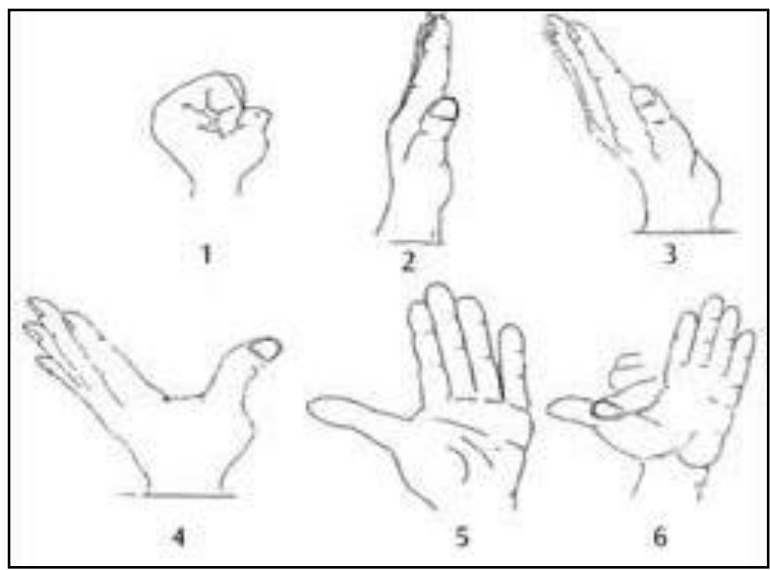

Şekil-2. Sinir kaydırma egzersizleri.

Kortikosteroid enjeksiyonu: Lokal kortikosteroid enjeksiyonu kanıta dayalı verilerde; plaseboya kıyasla enjeksiyondan bir ay sonra semptomlarda daha büyük klinik iyileşme sağlar. Bir ayın ötesinde belirgin semptom hafiflemesi gösterilmemiştir. Lokal kortikosteroid enjeksiyonu üç aya kadar oral kortikosteroidden anlamlı derecede iyi klinik iyileşme sağlar. Lokal kortikosteroid enjeksiyonu, anti-enflamatuar tedaviye ve sekiz hafta sonra splintlemeye veya altı ay sonra Helyum-Neon lazer tedavisine kıyasla klinik sonucu anlamlı şekilde iyileştirmez. İki lokal kortikosteroid enjeksiyonu bir enjeksiyona kıyasla anlamlı ek klinik fayda sağlamamaktadır (12). Kortikosteroid enjeksiyonları operasyon intiyacını geciktirebilir. Tek bir $80 \mathrm{mg}$ metilprednizolon, $40 \mathrm{mg}$ metilprednizolon veya salin enjeksiyonu ile tedavi edilen 111 hastanın çift-kör randomize kontrollü çalışmasında plaseboya kıyasla metilprednizolon enjeksiyonları ve $80 \mathrm{mg}$ enjeksiyondaki hastalar ile 10 haftada daha büyük bir iyileşme gösterdiği ve 12 ayda ameliyat geçirme olasılığının azaldığı bildirilmiştir (13). Ultrason eşliğinde enjeksiyonlar daha güvenli ve doğru bir girişim sağlamaktadır. Kör enjeksiyonlara göre semptom şiddeti açısından daha etkili, fonksiyon ve elektrofizyolojik testler açısından farklı değildir (14).

Oral medikal tedaviler: Oral steroid; $20 \mathrm{mg}$ metilprednizolon 10-14 gün kullanımı plaseboya göre ağrı ve fonksiyon üzerine etkin, ancak lokal steroide üstün değildir. Non-steroid anti- 
inflamatuar ilaçlar (NSAii), diüretik, vitamin B6'nın etkin olmadığı bildirilmektedir.

KTS'de 50 yaşın üzerinde olma, semptomların 10 aydan daha uzun süredir devam ediyor olması, sürekli parestezik yakınmaların varlığı, stenozan fleksör tenosinovit ve 30 sn'den uzun süren Phalen testi olumluluğu prognozu kötü etkilemektedir (15).

\section{Kubital Tünel Sendromu}

Kubital tünel sendromu, karpal tünel sendromundan sonra en sık görülen tuzak nöropatidir. Kübital tünel sendromunda hasta eğitimi ve aktivite modifikasyonu, semptomları artıııcı hareketlerin tekrarından kaçınılması açısından oldukça önemlidir. İlk dönemde amaç, ağrı, yüklenme ve inflamasyonun azaltılmasıdır. Dirseği istirahate almak, inflamasyonu baskılayıp semptomlarda azalma sağlar. Dirsek düzeyi ulnar nöropatisi olan hastalara, splint kullanımına ek olarak, lokal steroid enjeksiyonu uygulanmasının tedaviye ek yarar sağlamadığı belirtilmektedir. Altı ila 12 haftalık konservatif tedaviye yanıt yoksa progresif paralizi, uzun süreli lezyon varlığını gösteren klinik kanıtlar eşlik ediyorsa (kas atrofisi, pençe el) cerrahi tedavi düşünülmelidir (16).

Hasta eğitimi ve aktivite modifikasyonu: Telefonu diğer elle tutmak, çalışırken dirsek üzerine dayanmamak, dinlenirken kolu uyluk üzerinde supinasyonda tutmak ve destek pedleri kullanmak önerilebilir.

İstirahat: Ağrı, yüklenme ve enflamasyonun azaltılması için dirseği 30-45 derece fleksiyonda tutan ticari / termoplastik splintler kullanılır. 6-12 hafta kullanılması önerilir. Günde 2-3 kez splint çıkarıp eklem hareket açıklığı egzersizi yapılır. 12 hafta gece splinti ve aktivite modifikasyonu kombine edildiğinde hafif / orta düzey etkilenmesi olan vakalarda başarılı sonuçlar bildirilmiştir (17).

Steroid enjeksiyonu: Steroid enjeksiyonunun sinir alanını azalttığı birkaç çalışmada gösterilse de fonksiyonel ya da semptomatik sonuçlar vakalarda benzer bulunmuştur (18).

Diğer tedaviler: Ultrason, lazer ve mobilizasyon tekniklerine yönelik yeterli çalışma yoktur.

Ağrı azaldıkça splint çıkarılır ve dirsek, el bilek eklem hareket açıklığı, germe, güçlendirme ve sinir kaydırma egzersizleri (Şekil-3) verilir (19).

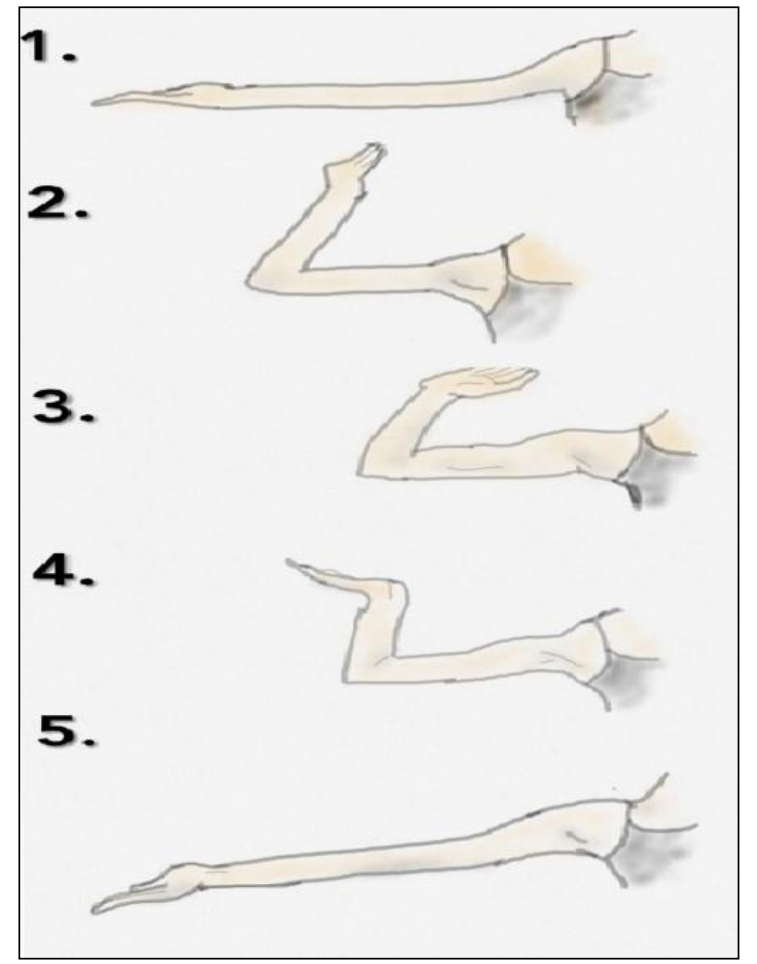

Şekil-3. Sinir kaydırma egzersizleri.

\section{Tarsal Tünel Sendromu}

Tarsal tünel sendromu, tibial sinir veya dallarının (medial plantar, lateral plantar ve kalkaneal sinirler) ayak bileğinin medialinde, fleksör retinakulumun altında, fibro-osseöz tünelde sıkışması sonucu ortaya çıkan bir tuzak nöropatidir (20).

Konservatif tedavide istirahat, immobilizasyon, ortezler, NSAil, lokal kortikosteroid enjeksiyonları, fizyoterapi ve kilo verme önerilir. İmmobilizasyon için ayak - ayak bileği ortezleri kullanılır. Fleksibl bir ayak deformitesi mevcutsa, ayağı nötral pozisyonda tutacak bir ortez etkili olabilir. Fleksibl valgus deformitesi olan topukta, medial longitudinal arkus destekleri ve medial topuk kamaları başarılı sonuçlar vermektedir. Lateral topuk kamalar, fleksibl varus topuklarını etkili olarak tedavi eder; bu olgularda medial longitudinal arkus desteklerinden kaçınılmalıdır. Dorsifleksiyonla semptomları artan hastalarda, 1 inç'lik topuk desteği, tibial sinir üzerindeki gerilimi azaltarak semptomların iyileşmesine yardım eder. Intrensek ayak kaslarını, fleksör dijitorum longus, fleksör hallusis longus ve tibialis posterior kaslarını güçlendirme egzersizleri, mediyal longitudinal arkı desteklemek ve ayağı nötral pozisyonda stabilize etmeye yardımcı olmak için önerilir. Nöral mobilizasyon, yumuşak doku 
mobilitesini iyileştirmek için kullanılır (21). Bu tedaviler ile ağrının, inflamasyonun ve dokudaki stresin azaltılması ile kas gücü, fleksibilite, alt ekstremite yumuşak doku mobilitesinin restorasyonunun sağlanması amaçlanır $(20,21)$.

\section{Morton Nöroma}

Morton nöroma, ön ayak ve parmaklara vuran ağrı ile karakterizedir. İnterdigital sinirin, transvers intermetatarsal ligament altında basısı sonucu gelişen klinik tablodur (22). Zıplama, koşma, çömelme, yüksek topuklu ve dar ayakkabı giyme ile ağrı şiddetlenir. Tedavinin temelinde, ön ayak bölgesine binen yüklerin ve sonuç olarak interdigital sinir geriliminin azaltılması vardır. Geniş burunlu, alçak topuklu ayakkabı tercih edilmelidir. Metatars destekli tabanlık kullanılır. Metatarsal ped santral 3. metatars başının proksimaline yerleştirilmelidir. $\mathrm{Bu}$ intermetatarsal aralığı genişletir. NSAii, kortikosteroid ve lokal anestezik madde enjeksiyonları ağrıyı azaltır. Literatürde; mobilizasyon, manipülasyon, metatarsal ped, geniş ayakkabı, ESWT, kortikosteroid enjeksiyonu, sklerozan madde enjeksiyonu, radyofrekans ablasyon, krionörolizis ve botulinum toksin enjeksiyonları tedavide önerilmektedir. Ancak ağrı üzerine güçlü kanıtlar mobilizasyon ve manipülasyon ile kortikosteroid enjeksiyonu lehinedir $(22,23)$.

\section{Kaynaklar}

1. Peterson A, Kincaid J. Rehabilitation of patients with neuropathies. In: Braddom RL (ed). Physical Medical Rehabilitation. $3^{\text {rd }}$ ed. Philadelphia: Saunders; 2007: 660-78.

2. Genç A, Tur BS: Tuzak Nöropatileri, In: Romatoloji, Düzgün N (ed): Pfizer İnflamasyon, Ankara, Türkiye 2011: 77-81.

3. Werner RA, Andary M. Carpal tunnel syndrome: pathophysiology and clinical neurophysiology. Clin Neurophysiol 2002; 113: 1373-81.

4. Van Rijn RM, Huisstede BM, Koes BW, Burdorf A. Associations between work-related factors and the carpal tunnel syndrome. A systematic review. Scand J Work Env Heal 2009;35:19-36.

5. Leggit JC. Proper indications and use of orthopedic braces. In: Seidenberg PH and Beutler A (eds) The Sports Medicine Resource Manual. $1^{\text {st }}$ ed. Philadelphia: Saunders; 2008: 483-94.

6. Sayfa MJ, Massy-Westropp N, O'Connor, Pitt V. Splinting for carpal tunnel syndrome. Cochrane Database Syst Rev 2012; 11 (7): CD010003.doi: 10.1002 / 14651858.CD010003.

7. Akalin E, El O, Peker O, et al. Treatment of carpal tunnel syndrome with nerve and tendon gliding exercises. Am J Phys Med Rehabil. 2002; 81 (2): 108-13.

8. Ballestero-Pérez R, Plaza-Manzano G, Urraca-Gesto A, et al. Effectiveness of nerve gliding exercises on carpal tunnel syndrome: A systematic review. J Manipulative Physiol Ther 2017; 40 (1): 50-9. doi: 10.1016/j.jmpt.2016.10.004.

9. Baysal O, Altay Z, Ozcan C, Ertem K, Yologlu S, Kayhan A. Comparison of three conservative treatment protocols in carpal tunnel syndrome. Int J Clin Pract. 2006; 60 (7): 820-8.

10. Horng YS, Hsieh SF, Tu YK, Lin MC, Horng YS, Wang JD. The comparative effectiveness of tendon and nerve gliding exercises in patients with carpal tunnel syndrome: a randomized trial. Am J Phys Med Rehabil 2011; 90 (6): 435-42.

11. Huisstede BM, Hoogvliet P, Franke TP, Randsdorp MS, Koes BW. Carpal tunnel syndrome: effectiveness of physical therapy and electrophysical modalities. an updated systematic review of randomized controlled trials. Arch Phys Med Rehabil 2018; 99 (8): 1623-34. e23. doi: 10.1016/j.apmr.2017.08.482.

12. Marshall S, Tardif G, Ashworth, N. Local corticosteroid injection for carpal tunnel syndrome. Cochrane Database Syst Rev 2007; 18 (2): CD001554.

13. Atroshi I, Flondell M, Hofer M, Ranstam J. Methylprednisolone injections for the carpal tunnel syndrome: a randomized, placebo-controlled trial. Ann Intern Med 2013;159(5):309-17.

14. Babaei-Ghazani A, Roomizadeh P, Forogh B, et al. Ultrasound-guided versus landmark-guided local corticosteroid injection for carpal tunnel syndrome: A systematic review and meta-analysis of randomized controlled trials. Archives of Physical Medicine and Rehabilitation 2018; 99: 766-75.

15. Kaplan SJ, Glickel SZ, Eaton RG. Predictive factors in the non-surgical treatment of carpal tunnel syndrome. J Hand Surg Br 1990;15 (1): 106-8. 
16. Şahin MŞ, Altun S, Kafa B. Kübital tünel sendromu ve ulnar sinirin diğer tuzak nöropatileri. TOTBiD Dergisi 2015; 14: 555-565 doi: 10.14292/totbid.dergisi.2015.77.

17. Shah CM, Calfee RP, Gelberman RH, Goldfarb CA. Outcomes of rigid night splinting and activity modification in the treatment of cubital tunnel syndrome. J Hand Surg Am 2013; 38 (6): 1125-30.e1. doi: 10.1016/j.jhsa.2013.02.039.

18. Kooner S, Cinats D, Kwong C, Matthewson G, Dhaliwal G. Conservative treatment of cubital tunnel syndrome: a systematic review. Orthop Rev (Pavia) 2019; 11 (2): 7955. doi: 10.4081/or.2019.7955.

19. Caliandro P, La Torre G, Padua R, Giannini F, Padua L. Treatment for ulnar neuropathy at the elbow. Cochrane Database Syst Rev. 2016 Nov 15;11:CD006839.

20. Akan KH, Ünay K. Ayak ve ayak bileğinde tuzak nöropatileri. TOTBID Dergisi 2015; 14: 585-96 doi: 10.14292

21. Uzunkulaoğlu A, İkbali Afşar S. Tarsal Tünel Sendromu. FTR Bil Der 2014; 17: 189-95.

22. Öznur A, Doral MN, Çil A, Atay Ö, Tetik O. Morton Nöroma. Acta Orthop Traumatol Turc 2002;36 Suppl 1: 82-6.

23. Matthews BG, Hurn SE, Harding MP, Henry RA, Ware RS. The effectiveness of non-surgical interventions for common plantar digital compressive neuropathy (Morton's neuroma): a systematic review and meta-analysis. J Foot Ankle Res 2019; 12: 12. doi: 10.1186/s13047-019-0320-7. 